\title{
A Construção do conhecimento histórico dos movimentos político-culturais da década de $1960 *$
}

Milton Joeri Fernandes Duarte

\section{RESUMO}

Esta pesquisa, teve como objetivo identificar e comparar as representações históricas produzidas pelas universidades e imprensa dos movimentos políticoculturais dos anos 60 com as representações utilizadas pelos alunos do ensino médio contemporâneo enquanto instrumento para entender a construção do conhecimento histórico em sala de aula.

Palavras-chave: Educação, História, Movimento Estudantil, Conhecimento Histórico.

A pesquisa intitulada "Representações dos movimentos político-culturais da década de 1960 nos jovens de Ensino Médio", desenvolvida entre os anos de 2003 e 2004, teve como principal objetivo identificar e comparar as representações históricas dos movimentos político-culturais dos anos 60 com as representações utilizadas pelos alunos do Ensino Médio para entender esses movimentos.

Foram entrevistados alunos do Ensino Médio participantes do movimento estudantil secundarista de São Paulo, que fazem parte da UMES (União Municipal dos Estudantes Secundaristas de São Paulo), entidade composta por dois milhões e meios de estudantes de ensino fundamental e médio, técnico, cursos supletivos, pré-vestibulares e cursos livres da capital paulista.

A construção de um modelo de análise deste tipo tem que considerar vários aspectos metodológicos. Primeiro, este modelo é uma construção interpretativa, baseado numa leitura das representações de alguns alunos que terminaram o Ensino Médio. Segundo, não se pretende que este modelo estabeleça uma espécie de patamar onde se assentam os níveis de conhecimento histórico, e no qual os jovens

\footnotetext{
* Esse artigo é uma adaptação do terceiro capítulo da dissertação de mestrado Representações dos movimentos político-culturais da década de 60 nos jovens de ensino médio. Defendida na Faculdade de Educação da USP em 2005. Orientação: Prof ${ }^{\mathrm{a}} \cdot \mathrm{Dr}^{\mathrm{a}}$. Katia Maria Abud.
} 
se movam de maneira progressiva, pois esses níveis muitas vezes se misturam nas narrativas dos entrevistados. Terceiro, o modelo é válido quando se trata de um grupo, não como um padrão de aprendizagem para um indivíduo. Finalmente, trata-se de um modelo que tenta caracterizar o conhecimento histórico de alguns alunos através das representações históricas destes no presente, no contexto da escola, dasua instituição (UMES) e do seu ambiente cultural (meios de comunicação, familia e amigos).

As explicações e representações históricas sobre os movimentos políticoculturais da década de 1960 têm influência direta, em grau de importância decrescente: dos meios de comunicação, da família, da sala de aula, instituições políticas e colegas, o que nos permite concluir que o conhecimento histórico escolar adquirido por esses alunos sofre uma forte mediação, principalmente, da "vida cotidiana"(EZPELETA e ROCKWELL, 1986, p.22).

\section{1- As representações dos alunos e a consciência histórica}

Os conceitos e imagens ideais sobre os jovens e seus movimentos políticoculturais na década de 60 expressam situações que, apesar de uma identificação inicial proporcionada pelas atitudes de rebeldia e transgressão da cultura jovem do período, essas atitudes, ao longo do tempo, são vivenciadas ou reconhecidas de uma outra forma pelos jovens da atualidade, construindo novas representações, que podem ajudar ou dificultar o entendimento do conhecimento histórico desses movimentos.

Mas o que é especificamente o histórico nas representações dos alunos entrevistados?

0 histórico é uma orientação temporal que une o passado ao presente de tal forma que confere uma perspectiva futura na realidade atual. 0 que fica evidenciado nas seguintes explicações comparativas entre os movimentos político-culturais dos anos de 1960 e os movimentos juvenis atuais: 


\section{Quadro 1}

\begin{tabular}{|c|c|}
\hline Anos 60 & Atualmente \\
\hline $\begin{array}{l}\text { "O jovem daquela época tinha mais vontade } \\
\text { política devido à própria situação, pois não } \\
\text { vivíamos numa democracia" }\end{array}$ & $\begin{array}{l}\text { "O jovem de hoje é mais acomodado, pois } \\
\text { vivemos numa democracia" }\end{array}$ \\
\hline $\begin{array}{l}\text { "Época de conquistas a favor da liberdade e } \\
\text { contra a censura" }\end{array}$ & $\begin{array}{l}\text { "Os jovens já têm o seu espaço em várias } \\
\text { instituiçōes da sociedade: governo, partidos e } \\
\text { sindicatos". }\end{array}$ \\
\hline $\begin{array}{l}\text { "Período de muita luta e coragem, vitórias e } \\
\text { perdas contra a ditadura militar" }\end{array}$ & $\begin{array}{l}\text { "Movimento pacífico que não precisa pegar } \\
\text { em armas para lutar" }\end{array}$ \\
\hline $\begin{array}{l}\text { "Os movimentos políticos eram mais } \\
\text { amplos" }\end{array}$ & $\begin{array}{l}\text { "Os movimentos políticos são mais } \\
\text { segmentados" }\end{array}$ \\
\hline
\end{tabular}

Como podemos perceber através dos exemplos destacados, as representações dos alunos apresentam uma característica geral da consciência histórica e sua visão na vida prática atual, que serve como um elemento orientador e de identidade, dando a vida prática um marco e uma matriz temporal, uma concepção do "curso do tempo" que flui através dos assuntos mundanos e da vida diária. Essa consciência histórica evidencia um conhecimento histórico que serve principalmente para orientar as atividades humanas dos entrevistados evocando a experiência do passado ("período de muita luta e coragem, vitórias e perdas contra a ditadura militar") no presente ("movimento pacífico que não precisa pegar em armas para lutar") para criar expectativas futuras, ou seja, a história como um nexo significativo entre o passado, 0 presente e o futuro.

A consciência histórica tem uma função prática que confere á realidade uma direção temporal, uma orientação que pode guiar intencionalmente a ação através da mediação da memória histórica. Essa orientação temporal é formada por duas esferas: a vida prática (aspecto externo ao indivíduo), temporalidade marcada pela atividade humana; e a subjetividade interna dos atores, dimensão temporal da subjetividade humana (RÜSEN, 1992, p.29). Algo que toma uma forma mais concreta através da identidade histórica, onde a personalidade humana expande sua extensão temporal além dos limites da sua própria existência criando assim uma consciência histórica que pode ser exemplificada pelas representações dos estudantes em relação aos movimentos político-culturais da década de 1960. 
As representações construídas pelos alunos evidenciam a forma lingüística dentro da qual a consciência histórica realiza sua função de orientação, que é a narração. A narrativa constitui especificamente a consciência histórica na medida em que recorre às lembranças para interpretar as experiências do tempo. A lembrança é, para a constituição da consciência histórica, a relação determinante com a experiência do tempo. Algo que fica destacado quando o jovem torna-se objeto histórico de comparação ao longo do tempo:

\section{Quadro 2}

\begin{tabular}{|l|l|}
\hline "O jovem daquela época tinha mais vontade & "O jovem de hoje é mais acomodado, pois \\
política devido à própria situação, pois não & vivemos numa democracia" \\
vivíamos numa democracia" &
\end{tabular}

Esse tipo de relação com a experiência é o que está, afinal, na base da distinção entre a narrativa historiográfica e a ficcional. Esse recurso à lembrança deve ser pensado de forma que se trate sempre da experiência do tempo, cuja realidade atual deve ser controlada pela ação, mas que também admita ser interpretada mediante mobilização da lembrança de experiências de mudanças temporais passadas do jovem e de seu mundo. 0 passado é, então, como uma floresta para dentro da qual esses jovens, pela narrativa histórica, lançam suas indagações, a fim de compreenderem, mediante o que dela ecoa, o que lhes é presente sob a forma de experiência do tempo (mais precisamente: o que mexe com eles) e poderem esperar e projetar um futuro com sentido (RÜSEN, 2001, p.62).

Uma segunda especificação da narrativa como fundamento do conhecimento histórico na vida prática fica clara quando se examina mais de perto o processo referido, no qual a memória é propriamente induzida pela narrativa histórica. Neste ponto, a narrativa passa a constituir a consciência histórica ou conhecimento histórico ao representar as mudanças temporais do passado rememoradas no presente como processos contínuos, nos quais a experiência do tempo presente pode ser inserida interpretativamente e extrapolada em uma perspectiva de futuro. Isso é algo evidenciado em representações comparativas, onde a década de 1960 é apresentada como um período de lutas e conquistas que propiciou ao jovem de hoje ter um espaço de atuação nas esferas institucionais: 


\section{Quadro 3}

\begin{tabular}{|l|l|}
\hline $\begin{array}{l}\text { "Época de conquistas a favor da liberdade e "Os jovens já têm o seu espaço em várias } \\
\text { contra a censura" }\end{array}$ & $\begin{array}{l}\text { instituiçóes da sociedade: governo, partidos e } \\
\text { sindicatos" }\end{array}$ \\
\hline
\end{tabular}

Como podemos perceber, as mudanças no presente, experimentadas como carentes de interpretação, são interpretadas em articulação com os processos temporais rememorados do passado; a narrativa histórica torna presente o passado, de forma que o presente aparece como sua continuação no futuro. Com isso a expectativa do futuro vincula-se diretamente à experiência do passado: a narrativa histórica rememora o passado sempre com respeito à experiência do tempo presente e, por essa relação com o presente, articula-se diretamente com as expectativas de futuro que se formulam a partir das intenções e das diretrizes do agir humano dos estudantes entrevistados. Essa íntima interdependência de passado, presente e futuro é conhecida como uma representação da continuidade e serve à orientação da vida humana prática atual desses jovens(RÜSEN, 2001, p.64).

Uma terceira especificação da narrativa como operação intelectual decisiva para a constituição da consciência histórica dá-se quando se pergunta pelos critérios determinantes das representações da continuidade. Esses critérios encontram-se vinculados à constituição de sentido sobre a experiência do tempo mediante a narrativa histórica do entrevistado, pois se trata afinal de contas da identidade daquele que tem de produzir esse sentido da narrativa histórica, a fim de poder orientar-se no tempo. Toda narrativa histórica esta marcada pela intenção básica do narrador e dos jovens de seu convívio de não se perderem nas mudanças de si mesmo e de seu mundo. A experiência do tempo é sempre uma experiência da perda iminente da identidade do homem. Portanto, os jovens entrevistados constroem suas representações a partir das interpretações das mudanças temporais em que estão envolvidos a fim de continuarem seguros de si e de não terem receio de perder-se nelas. Como fica destacado na representação de radicalização política necessária dos anos 1960, simbolizada pela luta armada, contrapondo-se aos movimentos pacíficos do presente, já que não vivemos mais sob uma ditadura militar: 


\section{Quadro 4}

\begin{tabular}{|l|l|}
\hline $\begin{array}{l}\text { "Período de muita luta e coragem, vitórias e } \\
\text { perdas contra a ditadura militar" }\end{array}$ & $\begin{array}{l}\text { Movimento pacífico que não precisa pegar } \\
\text { em armas para lutar" }\end{array}$ \\
\hline
\end{tabular}

Trata-se de um esforço de auto-afirmação mediante representações de continuidade, com as quais os jovens relacionam as experiências do tempo com as intenções no tempo: a medida da possibilidade e da consciência dessa relação, ou seja, o critério de sentido para a constituição de representações abrangentes da continuidade é a permanência de si mesmos na evolução do tempo. A narrativa histórica é um meio de constituição da identidade humana e desses jovens entrevistados(RÜSEN, 2001, p.65-66).

Essa competência narrativa sempre está ligada à orientação temporal, dando sentido ao passado através de três elementos, que se encontram mesclados: forma, conteúdo e função.

Em relação ao conteúdo pode-se falar da "competência para a experiência histórica", que é a habilidade de experiências temporais capazes de olhar o passado e resgatar sua qualidade temporal diferenciando-o do presente, como, por exemplo, a competência de entender os movimentos político-culturais como fatos históricos ligados à luta contra a ditadura militar. Quanto á forma, pode-se dizer da "competência para a interpretação histórica", que reduz as diferenças do tempo entre o passado, o presente e o futuro através de uma concepção de um todo temporal significante que abrange todas as dimensões do tempo, como, por exemplo, integrar a luta estudantil da década de 1960 com as características dos movimentos juvenis atuais. Finalmente, em relação á função pode-se destacar a "competência de orientação", capaz de utilizar o todo temporal, com o seu conteúdo de experiência, para os propósitos de orientação de vida, que procura legitimar os movimentos juvenis atuais e articular a construção de uma identidade histórica entre esses estudantes.

Essa tipologia elaborada por Rüsen revela e define fundamentalmente os procedimentos da consciência histórica ou conhecimento histórico dando algumas indicações básicas sobre a "formação histórica" dos alunos. Com a expressão "formação histórica" o autor refere-se a todos os processos de aprendizagem em que a história é o assunto e que não se destinam, em primeiro lugar, à obtenção de competência profissional. Trata-se de um campo a que pertencem inúmeros 
fenômenos do aprendizado histórico: o ensino de história nas escolas, a influência dos meios de comunicação de massa sobre a consciência histórica e o fator da vida humana prática (família, instituições e colegas), o papel da história na formação dos jovens estudantes como influente sobre a vida cotidiana - em suma o campo do conhecimento histórico é extremamente heterogêneo. É nele que se encontram, além dos processos de aprendizagem específicos da ciência da história, todos os demais que servem á orientação da vida prática mediante consciência histórica, e nos quais o ensino da história (no sentido mais amplo do termo: como exposição de saber histórico com o objetivo de influenciar terceiros) desempenha algum papel (RÜSEN, 2001, p.48).

A experiência do passado representa, no relato dos alunos entrevistados, mais que a matéria-prima bruta de histórias produzidas para fazer sentido, mas algo que já possui, em si, a propriedade de estar dotado de sentido, de modo que a constituição consciente de sentido da narrativa histórica se refere diretamente a ela e lhe dá continuação, engendrando vários ingredientes das operações conscientes do pensamento histórico. 0 que possibilita a eles uma representação mais abrangente, mesmo que superficial e parcial, do processo histórico contemporâneo, quando, por exemplo, fazem uma comparação dos movimentos políticos dos dois períodos, atentando para o fato da abrangência dos movimentos da década de 60 (esfera pública) e a segmentação dos movimentos atuais (esfera privada):

\section{Quadro 5}

\begin{tabular}{|l|l|l|l|}
\hline $\begin{array}{l}\text { "Os movimentos políticos eram mais "Os movimentos políticos sảo mais } \\
\text { amplos" }\end{array}$ & \begin{tabular}{l} 
segmentados" \\
\hline
\end{tabular}
\end{tabular}

0 passado passa a ser articulado, como estado de coisas, com as orientações presentes no agir contemporâneos dos jovens, assim como as determinações de sentido, com as quais o agir humano organiza suas intenções e expectativas no fluxo do tempo, precisam também elas estar dadas como um fato da experiência atual(RÜSEN, 2001, p.73).

Portanto, as representações históricas dos alunos têm de ser pensadas como algo que emerge de determinados processos da vida humana prática. Como já foi enfatizado, a questão que se põe nos processos de constituição de 
sentido pela consciência histórica, não diz respeito, sobretudo, ou exclusivamente ao passado, mas à interdependência entre passado, presente e futuro, pois só nessa interdependência os homens conseguem orientar sua vida, seus atos, no tempo. Como representação de ação que se estende pelo passado, presente e futuro, a própria história faz parte dos atos, pois os atos da vida prática destes jovens pressupõem um mínimo de orientação no tempo.

Trata-se aqui de uma eficácia do passado no presente que não se refere à orientação intencional da vida prática atual. O passado é eficaz, como conjunto silencioso do agir, seja de modo implícito e natural, como, por exemplo, na "vida institucional" (escola, UMES e partido político), seja nos bastidores dos processos decisórios da "vida cotidiana" (influenciados por colegas, família e meios de comunicação).

Claro que nesse momento a história ainda não é abordada como ciência, mas trata-se de seus pressupostos concretos na vida prática, suas raízes, por assim dizer, na vida humana concreta, com as quais a história nunca chega a romper e a partir das quais a história nunca chega a romper e se constitui e cresce seja como processo de aprendizagem, seja como conhecimento científico. Com o termo raízes quer-se dizer duas coisas: de um lado, as necessidades de orientação percebidas pelos homens, agentes e pacientes, na experiência cotidiana do transcurso do tempo, em si mesmos e em seu mundo. De outro lado, a elaboração de uma determinada idéia de história, corresponde a essas necessidades de orientação que vem influenciar decisivamente a orientação prática da vida, no tempo(RÜSEN, 2001, p.22-23).

A maior parte das representações dos jovens secundaristas entrevistados, durante esta pesquisa, demonstrou a necessidade da consciência histórica (conhecimento histórico) para tratarem de valores morais e de argumentação moral (razão) e de como essa consciência vem sendo adquirida. Portanto, a consciência histórica é um pré-requisito necessário, pois se trata de uma mediação entre os valores morais (orientadores de comportamento) e a ação dos estudantes.

\section{2- 0 conhecimento histórico dos alunos e suas representações históricas}

Os alunos entrevistados, tal como os historiadores, precisam compreender por que motivos as pessoas atuaram no passado de uma determinada forma e 
o que pensavam sobre a forma como o fizeram, mesmo que não entendam isto tão bem quanto nós pesquisadores.

Desde o final da década de 1960 que historiadores vêm desenvolvendo várias pesquisas na área de investigação relacionada com o pensamento histórico dos alunos, fazendo com que essas representações possam ser analisadas enfatizando-se o contraste entre o sentido do "provisório" e do "definitivo", no pensamento do adolescente, o que introduz um elemento de incerteza nas conclusões históricas.

Como vários estudos de campo na área da Didática da História, realizados com adolescentes, esse estudo também concorda com essa visão geral do processo cognitivo de aprendizagem da História, pois depois dos 11-12 anos, o conceito de probabilidade torna-se organizado: há uma síntese entre acaso e operações, e estrutura-se um sistema de probabilidades (BARCA, 2000, p.35).

Uma das preocupações dessa pesquisa é demonstrar em que medida os jovens do Ensino Médio utilizam a provisoriedade e modelos definitivos de explicação histórica e, quando empregam um desses tipos de noções, que sentidos e quais as influências que estão por trás dessas explicações. Partindo do pressuposto que a progressão das idéias é algo comprovado nos alunos em relação à compreensão do processo histórico.

Embora essas idéias possam conduzir a dois caminhos em relação ao entendimento da História: impasse ou aprofundamento desse conhecimento.

Essa pesquisa procurou destacar alguns modelos dessa progressão do conhecimento histórico através das representações dos entrevistados em dois níveis:

\section{Nível 1 - Explicações em termos do que as pessoas pensavam naquele tempo}

- 0 jovem daquela época tinha mais vontade política devido à própria situação, pois não vivíamos numa democracia";

- Movimentos influenciados pela Guerra Fria, onde você tinha que se definir entre direita e esquerda";

- 0 jovem só tinha duas opções: luta pela liberdade ou ficar alienado, o que não era difícil devido ao medo e a repressão da época". 
Essas explicações evidenciam um ponto crucial do desenvolvimento da compreensão histórica destes jovens, pois demonstram que estes alunos compreendem que os jovens no passado tinham as mesmas capacidades para pensar e sentir que nós, mas não viam a realidade como nós vemos hoje. Para estes jovens é necessário reconstruir esse passado através da cultura, do sistema de valores e até do senso comum atual, levando a uma re-significação dos anos 1960. Isto faz com que eles dêem um passo enorme na compreensão do processo histórico, porque significa que eles podem continuar a construir um conhecimento histórico considerando as situações atuais, que de outra forma poderiam paralisar este processo cognitivo.

\section{Nível 2 - Explicações em termos de um contexto material e de idéias mais amplas}

- Os movimentos políticos eram mais amplos";

- Período de muita luta e coragem, vitórias e perdas contra a ditadura militar";

- Luta pela liberdade e por espaço político e social na época da ditadura militar";

- Nos anos 60 o jovem tinha uma condição sócio-econômica melhor";

- Maior consciência e envolvimento político do jovem e das pessoas";

- Período de muita luta dos estudantes e forte repressão";

- Época de conquistas a favor da liberdade e contra a censura".

As representações destacadas neste nível mais amplo de compreensão histórica revelam que as idéias e valores dos jovens dos anos de 1960 estão relacionadas com o tipo de vida que têm, e não são apenas opções individuais. Compreender isto envolve pensar sobre as condições materiais nas quais viviam os jovens daquela época considerando o impacto que este fato tinha nos padrões de comportamento diários na sua forma de pensar e de sentir. Ao relacionar as idéias e valores do passado com as condições materiais, estes alunos compreendem que as convicções e práticas particulares se relacionam com um sistema de valores e práticas mais ou menos coerente que são o suporte do sujeito histórico. Os alunos relacionam crenças menores invocando, por exemplo, a luta contra a ditadura militar para explicar 
porque é que os estudantes da década de 1960 tinham maior consciência e envolvimento político do que os jovens de hoje.

Os dois níveis de conhecimento histórico exemplificados pelas representações dos alunos pressupõem um pensamento criativo em oposição a um pensamento reprodutivo, bem como o raciocínio sobre diversas possibilidades de interpretação histórica, pois encontramos referenciais definitivos e provisórios nos dois níveis de suas explicações.

0 definitivo pode ser identificado, quando esses jovens analisam os anos 60 no Brasil, pois apesar da intensa movimentação artístico-cultural evidenciada pelas provas projetivas apresentadas durante as entrevistas, como um momento de luta política contra a ditadura militar a partir de posições ideológicas muito bem definidas entre direita e esquerda. Posições políticas que se encontram fundamentadas a partir do fato do jovem da época ser contra ou se manter alienado em relação aos acontecimentos políticos do período.

A partir desse referencial definitivo gravitam os elementos provisórios das explicações históricas, que ficam mais evidentes quando os alunos constroem suas explicações fazendo uma comparação entre as características históricas da época e o período atual. Sua explicação é relativizada a partir do momento histórico presente, pois ressaltam o fato da intensa mobilização política em relação ao período atual encontrar-se condicionada à falta de democracia na ditadura militar, fazendo dela uma espécie de inimigo político comum a todos os estudantes. Ampliando assim os movimentos políticos do período e justificando assim a segmentação e o menor destaque político dado ao movimento estudantil atualmente.

Portanto, os elementos definitivos e provisórios destacados nas representações dos jovens secundaristas entrevistados, comprovam a importância dos valores e da argumentação moral na formação da consciência histórica (conhecimento histórico) dos estudantes, que servirão como orientadores de comportamento para a ação desses jovens na sociedade atual.

Os diferentes significados dos elementos definitivos e provisórios do conhecimento histórico do aluno podem ser compreendidos e trabalhados pelo professor em sala de aula. Estes significados salientam a contingência do conhecimento histórico e a necessidade de sua desconstrução, através de uma visão objetiva, que reconhece a possibilidade de diversas reconstruções válidas do passado com recursos e critérios históricos específicos. 


\section{Referências}

BARCA, Isabel. o pensamento histórico dos jovens. Braga: Centro de Estudos em Educação e Psicologia - Instituto de Educação e Psicologia Universidade do Minho, 2000.

DUARTE, Milton Joeri Fernandes Duarte. Representações dos movimentos políticoculturais da década de 60 nos jovens de ensino médio. São Paulo, Feusp, 2005 (Dissertação de mestrado).

EZPELETA, Justa \& ROCKWELL, Elsie. Pesquisa participante. São Paulo: Cortez, 1986. (Coleção educação contemporânea).

RÜSEN, Jörn. Razão bistórica - teoria da bistória: fundamentos da ciência bistórica. Brasília: UNB, 2001.

\section{The construction of knowledge historic of political-cultural activity in the $60^{5}$ years.}

\section{ABSTRACT}

This research, carried through for to get master heading, had as objective to identify and to compare the historical representations produced by the universities and the press of the politician-cultural movements of years 60 with the representations used for the students of average education contemporary while instrument to understand the construction of the historical knowledge in classroom.

KEY-WORDS: Teaching history, Culture, Student's activity, Historical knowledge. 